\title{
KAJIAN KONSEP ARSITEKTUR HIJAU PADA BANGUNAN PUSAT PERDAGANGAN NIPAH MALL
}

\author{
${ }^{1}$ Silvi Nurfai'ni Julianti, ${ }^{2}$ Yeptadian Sari. \\ ${ }^{1}$ Universitas Muhammadiyah Jakarta, ${ }^{2}$ Universitas Muhammadiyah Jakarta \\ silvinurfainijulianti@gmail.com ${ }^{1}$
}

Informasi Naskah

Diterima: 01/04/2021; Disetujui terbit: 14/06/2021; Diterbitkan: 30/06/2021;

http://journal.uib.ac.id/index.php/jad

\begin{abstract}
ABSTRAK
Indonesia merupakan negara yang memiliki iklim tropis, namun akibat dari adanya penebangan pohon, pencemaran polusi, pencemaran limbah, dan lain-lain yang dapat mengakibatkan terjadinya pemanasan global. Penerapan konsep arsitektur hijau sangat berdampak untuk mengurangi akibat dari pemanasan global dan menciptakan udara yang sehat untuk para manusia yang ada dilingkungan sekitarnya. Arsitektur hijau merupakan konsep desain yang memanfaatkan energi, memenuhi kebutuhan pada pengguna, ramah lingkungan serta harus menyesuaikan iklim setempat. Metode penelitian ini dilakukan dengan menggunakan metode kualitatif dengan pendekatan deskriptif. Metode dengan cara ini yang melihat keadaan nyata pada kondisi situasi yang sebenarnya secara tidak langsung dan selanjutnya melakukan analisis yang di deskripsikan sehingga mendapatkan hasil dan kesimpulan. Arsitektur hijau yang dapat diterapkan pada penelitian ini yang menjadi studi kasus yaitu sebuah mall yang berada di Makassar yang bernama Nipah Mall menggunakan enam prinsip-prinsip yaitu hemat energi, memanfaatkan kondisi dan sumber energi alami, menanggapi keadaan tapak pada bangunan, memperhatikan pengguna bangunan, meminimalkan sumber daya baru, holistik.
\end{abstract}

Kata Kunci: Arsitektur Hijau, Kualitatif, Nipah Mall

\begin{abstract}
Indonesia is a country that has a tropical climate, but the result of tree cutting, pollution defilement, waste pollution, and others that can lead to global warming. The application of the concept of green architecture has an impact on reducing the effects of global warming and creating healthy air for the people in the surrounding environment. Green architecture is a design concept that uses energy, meets the needs of users, is environmentally friendly and must adapt to the local climate. This research method is carried out using qualitative methods with a descriptive approach. Methods in this way that see the real situation in the real situation conditions indirectly and then carry out the analysis described so as to get results and conclusions. Green architecture that can be applied to this research is a case study, namely a mall in Makassar named Nipah mall using six principles, namely saving energy, utilizing conditions and natural energy sources, responding to the site condition of the building, paying attention to building users, minimizing a new, holistic resource.
\end{abstract}

Keyword: Green Architecture, Qualitative, Nipah Mall.

\section{Pendahuluan}

Indonesia merupakan negara yang memiliki iklim tropis, namun akibat dari adanya penebangan pohon, pencemaran polusi, pencemaran limbah, dan lain-lain yang dapat mengakibatkan terjadinya pemanasan global. Karena dari akibat pemanasan global ini sangat berdampak terhadap bumi yang mengakibatkan dikit demi sedikit bumi tidak bisa ditinggali, oleh sebab itu kita sebagai manusia harus menjaga dan merawat bumi dan linkungan sehingga dapat mengurangi efek dari pemanasan global tersebut. Dapat kita ketahui kerusakan alam yang disebabkan oleh manusia salah satunya seperti mendirikan sebuah bangunan tanpa melihat atau merespon lingkungan di site dan 
disekitar site, hanya mementingkan keindahan dan estetika tanpa melihat penghijauan yang ada di sekitarnya. Hal ini tentu menjadi permasalahan yang besar bagi kelangsungan hidup untuk kedepannya.

Sebuah permasalahan pastinya harus memiliki solusi untuk mengatasi permasalahan tersebut atau menghentikannya, yaitu dengan cara mengkonsepkan bangunan dengan menggunakan konsep arsitektur hijau mulai dari perencanaan hingga perancangan. Penerapan arsitektur hijau sangat diperlukan pada bangunan, karena dapat memberikan dampak untuk mengurangi akibat dari pemanasan global dan menciptakan udara yang sehat untuk para manusia yang ada dilingkungan sekitarnya. Konsep arsitektur hijau merupakan konsep yang akan di desain dengan memiliki kriteria yang mendukung, seperti memanfaatkan energi, memenuhi kebutuhan pada pengguna, ramah lingkungan serta harus menyesuaikan iklim setempat. Sebagai contoh bangunan yang akan diteliti yaitu bangunan pusat perdagangan atau yang disebut mall. Pusat perdagangan merupakan bangunan yang bersifat publik yang bertujuan untuk menjual belikan barang-barang yang dibutuhkan maupun kesenangan. Harapan untuk bangunan publik atau khususnya bangunan pusat perdagangan yang menerapkan beberapa nilai untuk kepentingan lingkungan sekitarnya maupun pengguna.

\section{Kajian Pustaka}

\subsection{Pengertian Arsitektur Hijau}

Arsitektur hijau menurut (Priatman, 2002) adalah arsitektur yang memikirkan dengan lingkungan dan kepedulian tentang konservasi lingkungan global alami dengan penekanan pada efisiensi energi, pola berkelanjutan dan pendekatan holistik. Menurut Siregar (2012), arsitektur hijau adalah pelestarian alam dan lingkungan dengan mengutamakan efisiensi energi atau arsitektur ramah lingkungan (Mauludi, Anisa, Satwikasari, 2002), hal tersebut dapat dilihat pada gambar dibawah ini.

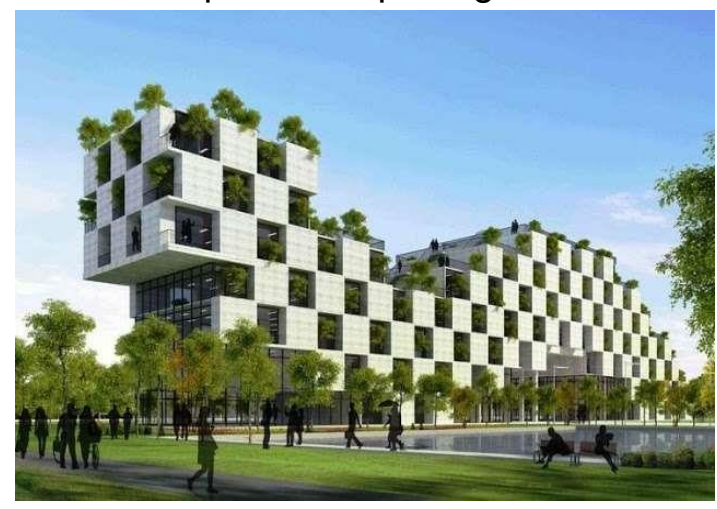

Gambar 1 Bangunan Beradaptasi Dengan Lingkungan

Sumber: arsitektur.com, 2020

Menurut Pradono (2008) arsitektur hijau dapat disebut sebagai berkelanjutan, ramah lingkungan, dan bangunan dengan performa sangat baik. Konsep arsitektur hijau yang sudah lama berkembang di negara ini dapat diterapkan untuk mengurangi polusi udara di lingkungan perkotaan (Mauludi, Anisa, Satwikasari, 2002).

Arsitektur hijau adalah arsitektur yang memikirkan kesehatanan terhadap lingkungan dengan menggunakan minim mengkonsumsi sumber daya alam, termasuk energi, air, mineral, serta minim menimbulkan dampak negatif bagi lingkungan (Karyono, 2008). Karena bertujuan untuk menciptakan desain eco terhadap arsitektur lingkungan, 
alami dan berkelanjutan (Permata dan Sari, 2019).

Pada arsitektur hijau mempunyai konsep yang memanfaatkan keadaan sumber daya alam dari pada sumber buatan, yang dimana mengingatkan kesadaran pada dampak-dampak yang ditimbulkan pada manusia dengan menggunakan sumber energi buatan pada bangunan. Rumah kaca yang mengakibatkan iklim yang sering terjadi karena terganggunya ekologi membuat suhu menjadi meningkat, sehingga dapat menerapkan di arsitektur hijau dengan menggunakan energi, air, dan pengguna materialmaterial yang mempengaruhi bangunan terhadap kesehatan manusia (Henriyanto, 2016). Menurut Abimanyu Takdir Alamsyah arsitektur hijau adalah tema rancangan arsitektural atau produk pewujudan karya arsitektur yang berwawasan lingkungan, peduli terhadap kelestarian alam, mendukung keberlanjutan atau mengutamakan konservasi lingkungan, mengupayakan efisiensi bahan material maupun penggunaan energi dalam skala lokal atau global, bersifat holistik baik secara ekologis maupun antropologis, dalam konteks arsitektural maupun aspek lain yang berkaitan dengannya. Arsitektur hijau adalah sebutan bagi arsitektur yang membumi, cerminan hasil pemikiran arsitektural atau setiap karya arsitek, baik secara konseptual maupun secara naluriah (Mauludi, Anisa, Satwikasari, 2002).

Arsitektur hijau bukan hanya menanam rumput atau tanaman yang banyak bisa disebut arsitektur hijau, penjelasan dari arsitektur hijau yaitu bangunan yang memberikan manfaat atau kenyamanan terhadap lingkungan sekitarnya, memberikan ruang publik yang nyaman pada pengguna (Sudarwani, 2012).

Penerapan arsitektur hijau pada bangunan sangatlah penting, karena berdampak posif terhadap lingkungan. Penerapan arsitektur hijau juga harus dipikirkan mulai sejak perencanaan pembangunan, operasional, pemeliharaan, renovasi hingga pembongkaran. Kesimpulan dari penjelasan materi di atas, bangunan yang bisa menggunakan bahan material alam, hemat energi, dan ramah lingkungan yang sudah bisa disebut sebagai bangunan hijau.

\subsection{Prinsip-Prinsip Arsitektur Hijau}

Berikut ini adalah prinsip-prinsip arsitektur hijau (Brenda dan Vale, 1991), sebagai berikut:

1. Hemat Energi

2. Memanfaatkan Kondisi dan Sumber Energi Alami

3. Menaggapi Keadaan Tapak Pada Bangunan

4. Memperhatikan Pengguna Bangunan

5. Meminimalkan Sumber Daya Baru

6. Holistik

\subsection{Sifat-Sifat Arsitektur Hijau}

1. Berkelanjutan

2. Ramah Lingkungan

3. Bangunan Dengan Performa yang Baik

\subsection{Pusat Perdagangan}

Pusat perdagangan adalah tempat untuk kebutuhan manusia, pusat perdagangan tidak hanya menjadi tempat jual beli kebutuhan pokok, tetapi juga menjadi fasilitas 
yang ditawarkan.

Menurut Abdurrahmat dan Maryani secara sederhana pusat perdagangan dapat diartikan sebagai pertukaran barang dan jasa antara individu dan antar wilayah di permukaan bumi. Sedangkan pusat perdagangan menurut anorga dalam lahurensha yaitu tempat beraktivitasnya pembelian barang dengan maksud untuk dijual kembali kepada pedagang lain, konsumen akhir atau pemakai industri.

Pada jaman sekarang pusat perdagangan sudah lebih berkembang seperti adanya pusat perdagangan yang biasa disebut mall, menjadi salah satu tempat untuk perdagangan atau perbelanjaan. Pusat perdagangan menjadi tempat yang menarik untuk beraktivitas seperti belanja, berjalan-jalan, dan berdagang yang dilakukan oleh manusia.

\section{Metode Penelitian}

Metode penelitian ini dilakukan dengan menggunakan metode kualitatif dengan pendekatan deskriptif. Metode dengan cara ini yang melihat dengan keadaan nyata pada kondisi situasi yang sebenarnya secara tidak langsung dan selanjutnya melakukan analisis yang di deskripsikan. Metode penelitian ini yang bertujuan untuk menghasilkan sebuah gambaran yang sesuai dengan kenyataan yang terjadi pada objek penelitian, data, dan informasi yang didapatkan dengan pendekatan kajian literatur.

Menganalisis yang digunakan adalah mendeskripsikan hasil pengumpulan datadata yang sudah diperoleh kemudian dilakukan analisis kualitatif berdasarkan teori-teori yang sudah dikumpulkan. Hal ini dimaksud pada bangunan pusat perdagangan yang sudah dikumpulkan teori-teori yaitu tentang asitektur hijau.

Pada penelitian ini bangunan yang jadi studi kasus yaitu Mall Nipah Makassar yang berlokasi di Jl. Urip Sumoharjo, Panaikang, Panakkukang, Kota Makassar.

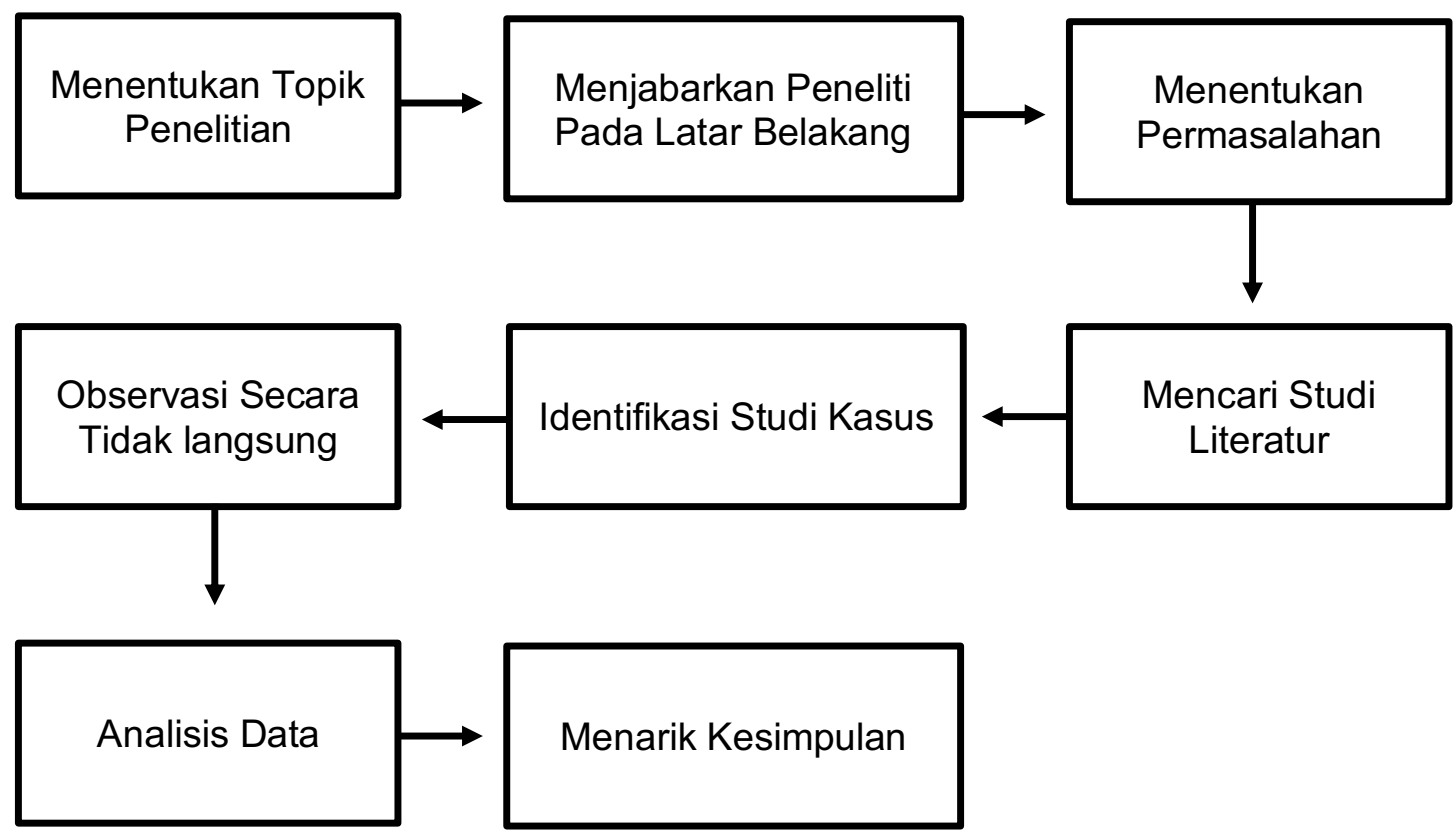

Gambar 2 Bagan Tahap Penelitian

Sumber: Dokumen Pribadi, 2020

80 I JAD - Vol.02/No.01, Juni 2021 


\section{Hasil dan Pembahasan}

Nipah Mall yang resmi dibuka pada akhir 2018, memberikan suasana baru di Kota Makassar. Karena mall ini menjadi kawasan komersial hijau pertama di Indonesia Timur yang menerapkan konsep arsitektur hijau, Nipah Mall mempertimbangkan dalam aspek lingkungan untuk konstruksi dan bangunan.

Nipah mall dapat dilakukan dengan pemanfaatan sumber daya, material dan penggunaan energi yang se-efisien mungkin. Dengan konsep terbuka, dapat mengurangi penggunaan penyejuk ruangan, ada instalasi pengolahan air limbah, sehingga memperhatikan semua aspek fasilitas ramah lingkungan di mall dapat dilihat dari setiap sudut bangunan.

Tanaman hias yang tumbuh hijau membentang dibagian depan sampai belakang juga terlihat hijau, seirama dengan bangunannya yang memang mengedepankan konsep arsitektur. Koridor void yang memberikan sirkulasi udara lebih segar, sejuk dan tampak terang serta luas.

Pengelolaan air yang dapat menampung air untuk digunakan dikolam dan penyiraman tanaman, kemudian waterfall atau air terjun yang berguna menjaga kelembaban udara. Daud Rianto menambahkan dengan konsep semi outdoor, dapat memberikan sirkulasi udara yang baik. Hal ini didukung dengan tanaman di semua area publik yang dapat mengurangi penggunaan energi pada area, baik itu dari segi pencahayaan maupun air conditioning.

1. Lokasi

Mall nipah yang terletak di Urip Sumoharjo, Panaikang, Panakkukang, kota Makassar. Mall nipah merupakan mal terbesar yang berada di Makassar, mall yang memiliki luas 3,5 hektar. Mall memliki 5 (lima) lantai, 1 (satu) basement dan gedung perkantoran yang berdiri 10 lantai. Mall berdiri di atas lahan seluas 3,5 hektar dan total building area sekitar 121.000 meter persegi, dipercantik dengan sentuhan gaya industrialis dan pemandangan natural pepohonan hijau.

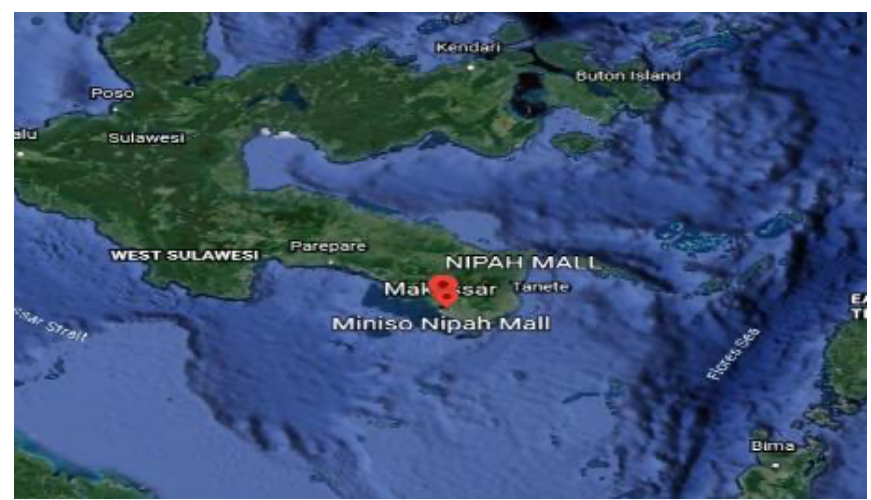

Gambar 3 Lokasi Mall Nipah

Sumber: Google earth, 2020

2. Gubahan Massa dan Bentuk Bangunan 
Bentuk dan gubahan dibawah ini bangunan dari bentuk bangunan Nipah Mall yang berkonsep arsitektur hijau yang menjadi bangunan ramah lingkungan,

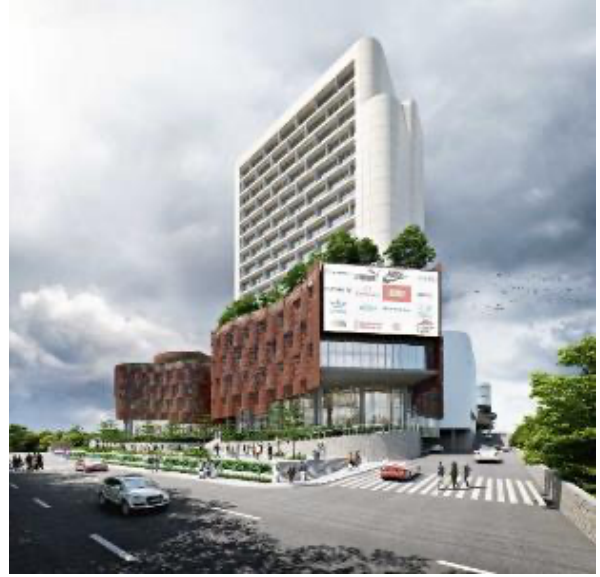

Gambar 4 Bangunan Nipah Mall

Sumber: arsitag.com, 2015

3. Tata Ruang dan sirkulasi

Tanaman pada sirkulasi pejalan kaki untuk pelindung dari panas akibat radiasi matahari, vegetasi yang diletakan pada ruang luar ataupun selasar mall. Konsep tata ruang terbuka yang menjadi sumber sirkulasi udara, hadirnya berbagai tanaman hijau yang tumbuh dan menghiasi seluruh area mall menjadi salah satu sumber sirkulasi udara membuat area mall menjadi bersih, nyaman dan segar.

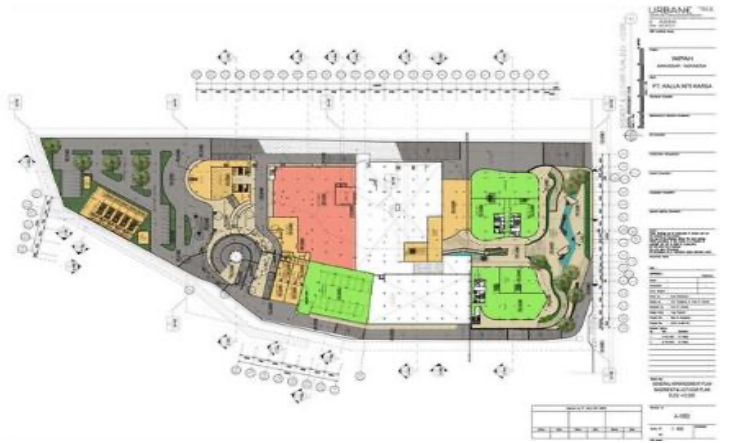

Gambar 5 Basement \& Lower Ground Floor Plan

Sumber: skyscrapercity.com, 2009

4. Fasad dan Tampak Bangunan

Tampak bangunan pada Nipah Mall ini menggunakan material yang terekspos

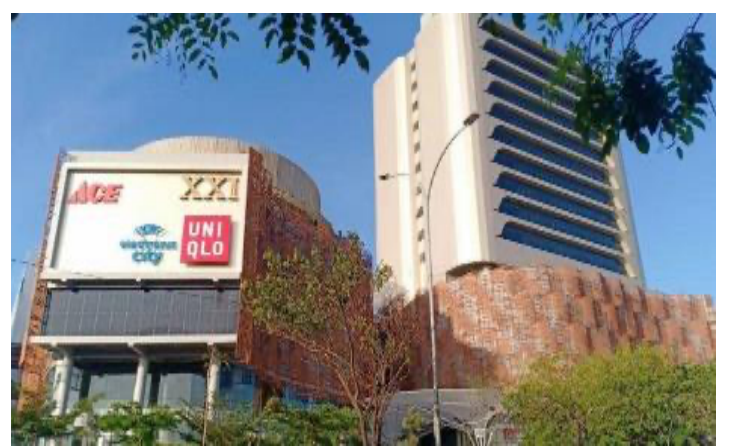

yang merupakan material utama berupa beton, kayu, batu bata dan terracotta, yang berkombinasi sehingga membentuk atmosfer Nipah.

82 I J $\mathbf{A}$ - Vol.02/No.01, Juni 2021 
Gambar 6 Tampak Nipah Mall

Sumber: tribunmakassar.com, 2020

\section{Struktur Bangunan}

Atap Mall Nipah memperlihatkan strukturnya tidak ditutupi, dan menggunakan material yang dapat menghindari efek matahari pada atap gedung dengan penggunaan material membran dilengkapi insulasi.

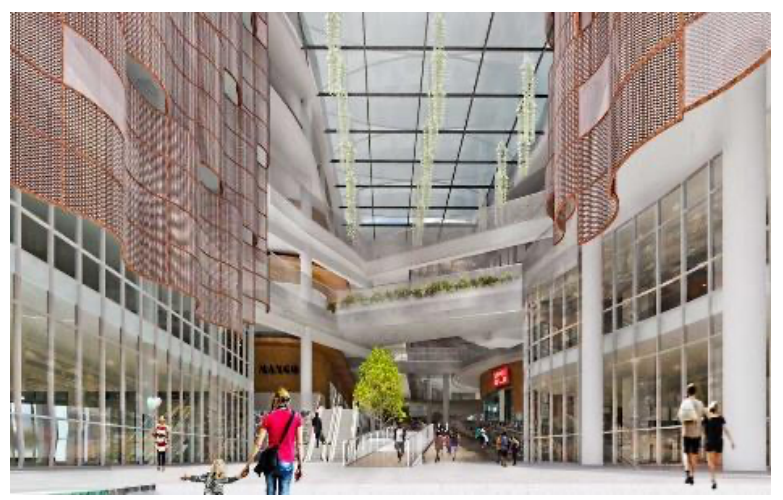

Gambar 7 Struktur Bangunan

Sumber: arsitag.com, 2015

\section{Analisis}

\section{a. Hemat Energi}

Hemat energi adalah unsur penting dari sebuah kebijakan energi. Penghematan energi dapat menurunkan konsumsi energi dan permintaan energi, sehingga dapat menutupi peningkatan kebutuhan energi akibat pertumbuhan populasi. Hal ini dapat mengurangi naiknya biaya energi, dan dapat mengurangi kebutuhan pembangkit energi atau impor energi. Berkurangnya pada permintaan energi sehingga dapat memberikan fleksibilitas dalam memilih metode produksi energi.

1. Listrik

Studi kasus yang kedua yaitu, Mall Nipah Makassar, studi kasus ini yang akan dianalisis dengan menggunakan prinsip-prinsip arsitektur hijau dengan menggunakan prinsip pertama yaitu hemat energi. Mall Nipah ini menggunakan jendela pasif dan pada bagian tampak bangunan dan menggunakan material kaca. Pada desain tampak mall nipah Makassar tidak seluruhnya full mengunakan kaca tapi dikombinasi dengan beton bertulang, tetapi lebih dominan menggunakan kaca, apabila dilihat dari tampak depan material kaca yang digunakan terlihat sedikit dikarenakan material kaca memiliki lapisan lagi yaitu berupa secondary skin.

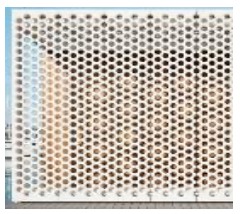




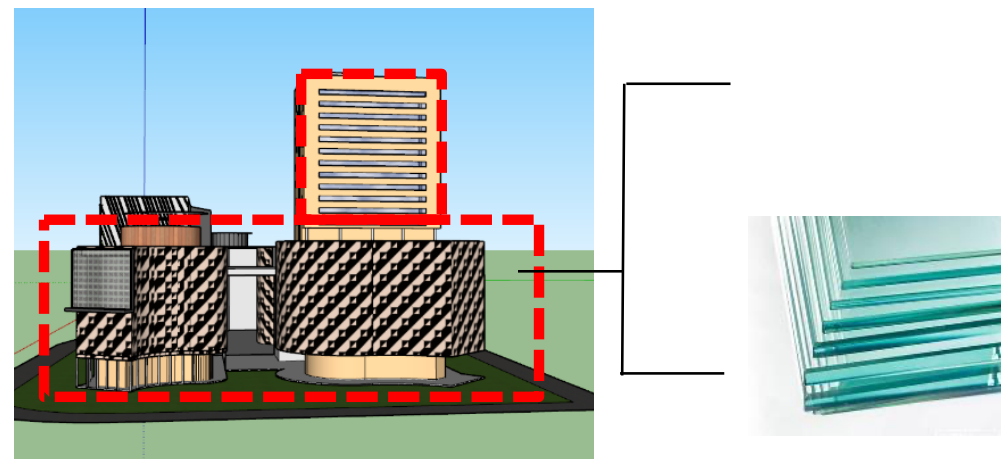

Gambar 8 Seconday Skin Bangunan

Sumber: Dokumen Pribadi, 2020

2. Orientasi Bangunan

Pada bangunan Mall Nipah Makassar memiliki orientasi bangunan yang merespon terhadap iklim yang ada di daerah tersebut, karena pada Bangunan Mall Nipah Makasar sisi terpanjang pada fasad bangunan menghadap ke arah utara dan selatan. Sehingga dapat mengurangi radiasi matahari yang dapat menyebabkan kepanasan dan tidak nyaman yang berlebihan bagi pengguna bangunan.

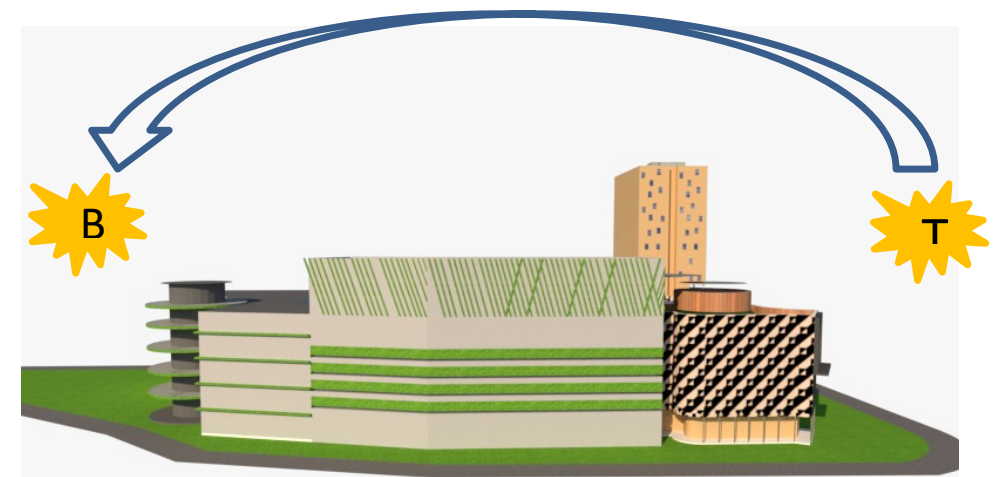

Gambar 9 Orientasi Bangunan Mall Nipah Makasar

Sumber: Dokumen Pribadi, 2020

b. Memanfaatkan Kondisi Dan Sumber Daya Energi Alami

84 I J $\mathbf{A}$ - Vol.02/No.01, Juni 2021 
Membangun harus berdasarkan iklim yang berlaku dilokasi tapak bangunan agar bangunan yang didesain bisa merespon iklim yang ada pada lokasi tersebut. Nipah Mall dapat dilakukan dengan pemanfaatan sumber daya, material dan penggunaan energi yang seefisien mungkin. Dengan konsep terbuka, dapat mengurangi penggunaan penyejuk ruangan, ada instalasi pengolahan air limbah, sehingga memperhatikan semua aspek fasilitas ramah lingkungan di mall dapat dilihat dari setiap sudut bangunan. Gambar di bawah ini adalahlah semi outdor dari bangunan Mall Nipah Makassar.

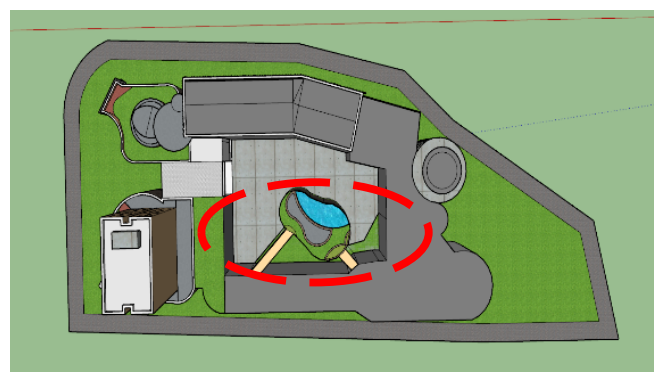

Gambar 10 Pencahayaan Mall Nipah

Sumber: Dokumen Pribadi, 2020

Tanaman hias yang tumbuh hijau membentang dibagian depan sampai belakang juga terlihat hijau, seirama dengan bangunannya yang memang mengedepankan konsep arsitektur. Koridor void yang memberikan sirkulasi udara lebih segar, sejuk dan tampak terang serta luas.

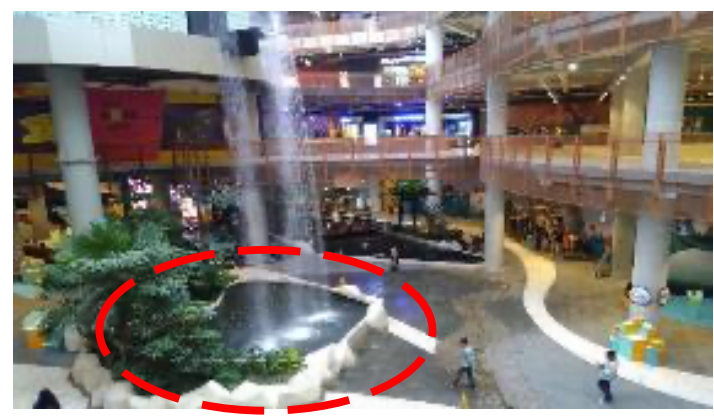

Gambar 11 Pencahyaan Mall Nipah

Sumber: ekonomi.bisnis.com, 2018

Pengelolaan air yang dapat menampung air untuk digunakan dikolam dan penyiraman tanaman, kemudian waterfall atau air terjun yang berguna menjaga kelembaban udara. Daud Rianto menambahkan dengan konsep semi outdoor, dapat memberikan sirkulasi udara yang baik. Hal ini didukung dengan tanaman di semua area publik yang dapat mengurangi penggunaan energi pada area, baik itu dari segi pencahayaan maupun air conditioning.

\section{c. Menanggapi Keadaan Tapak Pada Bangunan}

Kebutuhan arsitektur hijau harus memperhatikan kondisi pemakaian yang didirikan di dalam perencanaan dan pengoperasiannya, memiliki lahan hijau yang tidak melewati 
lahan lingkungan lainnya. Mall Nipah Makassar mempunyai luas bangunan $121.426 \mathrm{~m}^{2}$, Mall Nipah ini menempati lahan yang luas, namun bentuk bangunan menanggapi bentuk tapak yang ada di site sebelum mall itu dibangun, mall ini memiliki pepohonan disekitar pejalan kaki dan mall ini tidak merusak lahan disekitarnya.

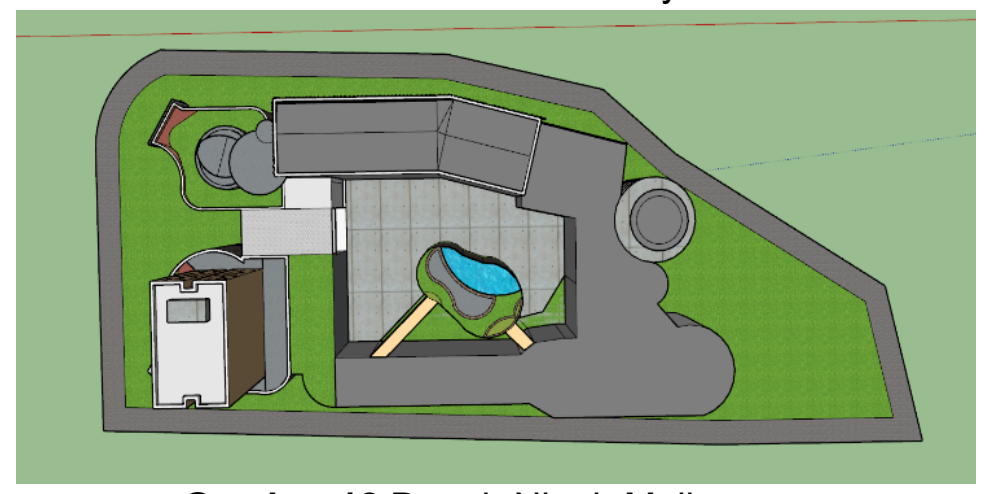

Gambar 12 Denah Nipah Mall

Sumber: Dokumen Pribadi, 2020

\section{d. Memperhatikan Pengguna Bangunan}

Kebutuhan arsitektur hijau harus memperhatikan kondisi pemakaian yang didirikan di dalam perencanaan dan pengoperasiannya. Kriteria bangunan arsitektur hijau yaitu bangunan yang desainnya mulai dari perencanaan hingga perancangan sudah memikirkan dari pengguna bangunan itu sendiri, sehingga apabila bangunan itu sudah berdiri dan digunakan oleh pengguna nya maka si pengguna merasakan nyaman dan betah ketika berada pada bangunan itu.

1. Universal

Nipah mall menyediakan ramp pada pengunjung disabilitas supaya pengunjung yang datang ke Nipah Mall merasakan kenyamanan saat berbelanja tanpa harus kesulitan.

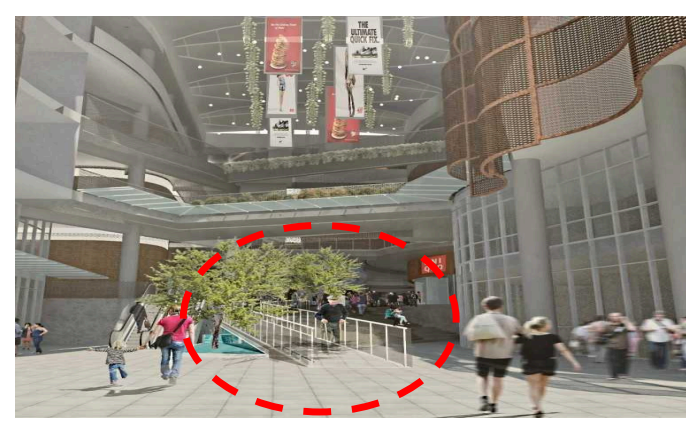

Gambar 13 Ramp Mall Nipah

Sumber: arsitag.com, 2015

2. Material Dinding Dan Lantai

Desain Mall Nipah menggunakan material yang dapat menghindari efek heat island pada atap gedung dengan penggunaan material membran dilengkapi insulasi, tetapi ada beberapa poin yang tidak terpenuhi mengenai atap. Sedangkan material pada ruang terbuka untuk permukaan jalur pedestrian menggunakan material batu alam andesit baik di ramp belakang maupun entrance 
bangunan.

Gambar 14 Material Nipah Mall

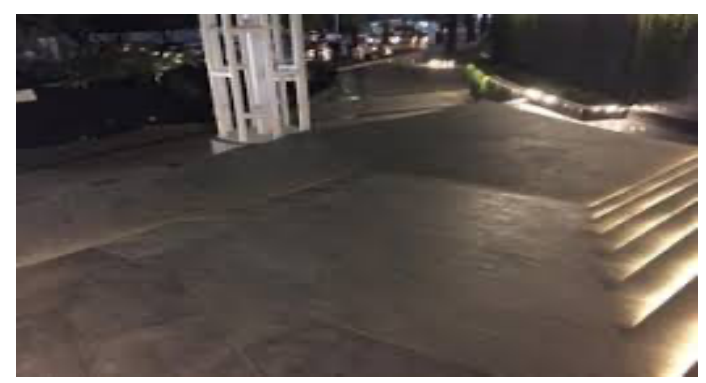

Sumber: ekonomi.bisnis.com, 2018

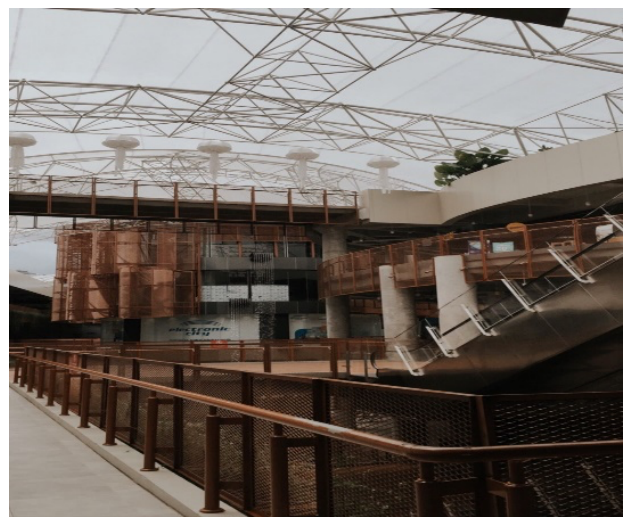

Gambar 15 Material Nipah Mall

Sumber: ekonomi.bisnis.com, 2018

e. Meminimalkan Sumber Daya Baru

Adapun konsep interiornya sendiri menggunakan material ekspos sebagai material utama berupa concrete/beton, kayu, metal, batu bata dan terracota, kombinasi inilah yang membentuk atmosfir Nipah. Menariknya, dengan konsep bangunan hijau, Daud mengaku telah merasakan dampaknya secara ekologi dan ekonomi.
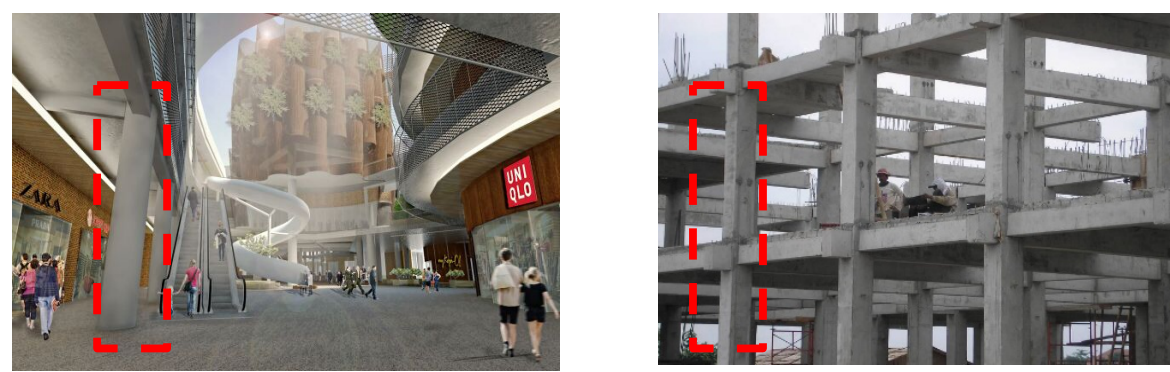

Gambar 16 Nipah Mall

Sumber: arsitag.com, 2015

\section{f. Holistik}

Mall Nipah secara menyeluruh telah menerapkan prinsip-prinsip dari arsitektur hijau yang dimana telah menerapkan bangunan hemat energi, memanfaatkan kondisi dan sumber daya alami, memperhatikan pengguna bangunan, dan meminimalkan sumber daya baru maka dari hasil nya Mall Pacific Pace dan Mall Nipah telah menerapkan konsep arsitektur hijau. 


\section{Kesimpulan}

Hasil dari penelitian yang telah di jabarkan pada bab-bab sebelumnya, menyimpulkan bahwa bangunan Mall Nipah di Makassar merupakan bangunan yang menerapakan pendekatan arsitektur hijau, maka kita dapat simpulkan bahwa setiap bangunan yang sudah menerapkan enam prinsip di bawah ini merupakan bangunan yang sudah menggunakan konsep bangunan aristektur hijau.

Berikut enam prinsip bangunan yang menerapkan arsitektur hijau:

1. Memahami bagaimana suatu bangunan yang bisa menghemat energi, dengan cara menerapkan prinsip bangunan hemat energi membuat bukaan lebih besar dan membuat sirkulasi udara agar udara luar bisa masuk mengalir kedalam bangunan kemudian keluar secara cross ventilation, dengan cara ini bangunan dapat mengurangi penggunakan listrik dan AC.

2. Bukaan yang akan dibuat pada desain bangunan juga harus memperhatikan aklimatisasi pada tempat bangunan yang akan di dirikan agar bisa memanfaatkan kondisi dan sumber energi alami.

3. Gubahan bentuk bangunan harus memperhatikan bentuk tapak site yang ada agar lingkungan disekitar tidak terganggu dan merusak lingkungan sekitar, dan memiliki peresapan yang cukup dan penghijauan disekitar bangunan.

4. Sebelum perencanaan atau perancangan bangunan juga sudah memikirkan bagaimana kondisi eksisting sekitar agar mempermudah nantinya pengguna bangunan sampai ke site.

5. Penggunaan material yang harus digunakan yaitu harus material yang dimana bisa didaur ulang atau digunakan bangunan berikutnya.

6. Holistik yaitu menerapkan seluruh prinsip satu sampai prinsip enam, maka apabila suatu bangunan sudah menerapkan 6 prinsip pendekan arsitektur hijau maka bangunan tersebut sudah menerapkan bangunan arsitektur hijau.

\section{Daftar Pustaka}

Arsitag. (2015). Arsitag.com. Retrieve Januari 27, 2021, Arsitag: https://www.arsitag.com/project/nipah-mall/photo/52839

Arsitur Studio. (2020). Arsitur.com. Retrieved Januari 27, 2021, Arsitur Studio: https://www.arsitur.com/2017/09/pengertian-green-architecture-prinsip.html Astuti, D. (2018) . Garuh Tata Ruang Kota Terhadap Pusat Perbelanjaan Di kawasan Plaza Jababeka.Jurnal IImiah Desain \& Konstruksi

Arifia, D., Soedwiwahjono., \& Utomo, P. R. (2017). Pengaruh Perkembangan Kegiatan Perdagangan Dan Jasa Terhadap Perubahan Penggunaan Lahan Di Kawasan Solo Baru.

Henriyanto, A. (2016). PERENCANAAN PUSAT TEKNOLOGI INFORMASI DI KENDARI DENGAN PENDEKATAN ARSITEKTUR HIJAU. Volume 1 No 2| Agustus 2016, 84.

Kasir, I. (2020). Bukamatanews.id. Retrieve November 28, 2020, Nipah Mall: https://bukamatanews.id/read/2020/03/19/efek-corona-jam-operasional-nipahmall-dan-mari-berubah

Mauludin, F. A., Anisa., \& Satwikasari, F. A. (2020). Kajian Prinsip Arsitektur Hijau pada Bangunan Perkantoran (Studi Kasus United Tractor Head office Dan Menara BCA). Jurnal Arsitektur SINEKTIKA Vol. 17 No. 2, 155-161

Munawaroh, S. (2018). ekonomi.bisnis.com. Retrieved Januari 27, 2021, Nipah Mal Makassar, Didesain Ridwan Kamil dan Bidik Kaum Milenial: https://ekonomi.bisnis.com/read/20181110/276/858485/nipah-mal-makassar-

88 I JA - Vol.02/No.01, Juni 2021 
didesain-ridwan-kamil-dan-bidik-kaum-milenial-

Permata, R. M., \& Sari, Y. (2019). Persepsi Pengunjung Terhadap Impelementasi Arsitektur Hijau Pada Bangunan Pusat Perbelanjaan. Jurnal Arsitektur PURWARUPA Vol. 3 No. 2, 137-143

Utsman, R. M., Suroto W., \& Winarto Y. (2020). Penerapan Prinsip Arsitektur Hijau Pada kantor sewa Di Surakarta.

Umar, H. (2020). Fajar.co.id. Retrieved November 28, 2020, Fajar Coid: https://fajar.co.id/2020/03/24/dukung-langkah-pemerintah-tanggulangi- coronanipah-mall-tutup-sementara/

Winastya, P. K. (2020). Merdeka.com. Retrieved Januari, 27, 2021, Proses Terjadinya Pemanasan Global: https://www.merdeka.com/trending/proses-terjadinyapemanasan-global-perlu-diketahui-kln.html?page $=5$ 